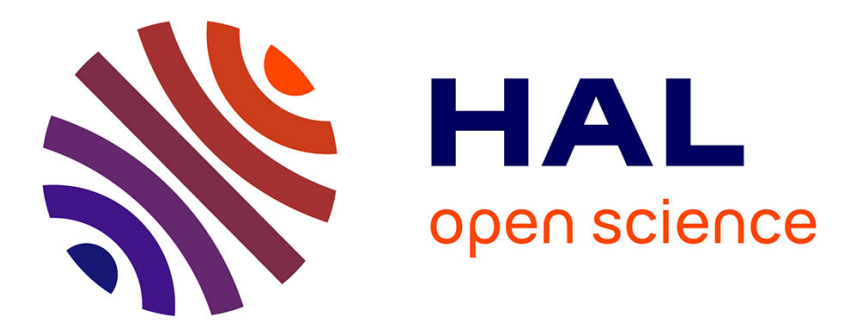

\title{
Synthesis of size-controlled UO2 microspheres from the hydrothermal conversion of U(IV) aspartate
}

V. Trillaud, Jérôme Maynadie, J. Manaud, J. Hidalgo, D. Meyer, Renaud Podor, N. Dacheux, Nicolas Clavier

\section{- To cite this version:}

V. Trillaud, Jérôme Maynadie, J. Manaud, J. Hidalgo, D. Meyer, et al.. Synthesis of size-controlled UO2 microspheres from the hydrothermal conversion of U(IV) aspartate. CrystEngComm, 2018, 20 (48), pp.7749-7760. 10.1039/C8CE01352G . hal-02007816

\section{HAL Id: hal-02007816 https://hal.umontpellier.fr/hal-02007816}

Submitted on 5 Feb 2019

HAL is a multi-disciplinary open access archive for the deposit and dissemination of scientific research documents, whether they are published or not. The documents may come from teaching and research institutions in France or abroad, or from public or private research centers.
L'archive ouverte pluridisciplinaire HAL, est destinée au dépôt et à la diffusion de documents scientifiques de niveau recherche, publiés ou non, émanant des établissements d'enseignement et de recherche français ou étrangers, des laboratoires publics ou privés. 


\section{Synthesis of size-controlled $\mathrm{UO}_{2}$ microspheres from the hydrothermal conversion of U(IV) aspartate}

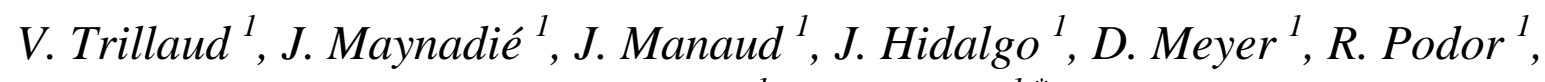
N. Dacheux ${ }^{l}$, N. Clavier ${ }^{1, *}$

${ }^{1}$ ICSM, CEA, CNRS, ENSCM, Univ Montpellier, Site de Marcoule, BP 17171, 30207 Bagnols/Cèze cedex, France

* Corresponding author:

Dr. Nicolas CLAVIER

ICSM, CEA, CNRS, ENSCM, Univ Montpellier

Site de Marcoule

BP 17171

30207 Bagnols sur Cèze

France

Phone : + 33466339208

Fax : + 33466797611

nicolas.clavier@icsm.fr 


\begin{abstract}
:
A simple wet chemistry route towards micrometric spherical $\mathrm{UO}_{2}$ particles was designed through the conversion of uranium(IV) aspartate under mild hydrothermal conditions $(\mathrm{T}=$ $160^{\circ} \mathrm{C}$ ). A multiparametric study examining the effects of hydrothermal treatment duration, initial uranium/aspartic acid molar ratio and magnetic stirring allowed us to point out the role of organic species in the shaping of the particles and to specify the operating conditions leading to monodisperse and size-controlled particles. In a turbulent flow regime (i.e. $\operatorname{Re}_{\mathrm{a}}>$ $10^{4}$ ), particles with diameter ranging from $400 \mathrm{~nm}$ to $2500 \mathrm{~nm}$ were obtained with a typical dispersion of less than $\pm 10 \%$. Moreover, the protocol was found to be robust and reproducible, with only limited size variation from one batch to another (typically less than $\pm 5 \%$ on the particle diameter). The effect of an additional heat treatment step was also investigated and showed that residual traces of water and organics can be removed after firing at $600^{\circ} \mathrm{C}$ without altering the initial morphology. This wet chemistry route appears to be very promising for the production of spherical $\mathrm{UO}_{2}$ particles and can be simply implemented in any nuclear chemistry lab, which paves the way to applications of such materials in various scientific areas.
\end{abstract}

\title{
Keywords :
}

Uranium oxide - conversion - hydrothermal - microsphere - nuclear safeguards 


\section{Introduction}

Among the numerous challenges linked to the development of advanced materials for the nuclear fuel cycle, the elaboration of shape-controlled powders has recently attracted a growing interest, especially for actinide-based oxides ${ }^{1}$. In this frame, most of the efforts concern the synthesis of spherical particles with perspective use in various applications. First of all, as $\mathrm{UO}_{2}$ and $(\mathrm{U}, \mathrm{Pu}) \mathrm{O}_{2}$ solid solutions are aimed to be used as fuels in future Gen III and/or Gen IV reactors ${ }^{2}$, spherical oxides with tailored size could help to improve the flowing capability of powders used in the fabrication process ${ }^{3,4}$ and could enhance the green density of the pellets before the sintering step. The design of uranium oxides particles with controlled shape and size is also required to qualify the analytical methods used for nuclear safeguards 5 , ${ }^{6}$. Uranium oxide nanospheres have already attracted some attention in view of their catalytic properties, particularly in the framework of the destruction of volatile organic compounds ${ }^{7}$. Lastly, polycrystalline spherical particles can be used as model samples to investigate the early stages of oxide ceramics ${ }^{8,9}$.

All these fields of research involve the preparation of spherical grains with variable size ranges, typically going from nanoparticles to sub-millimetric objects. For example, Hudry et al. recently prepared thorium, uranium, and even neptunium and plutonium oxide nanospheres (typically from 1 to $5 \mathrm{~nm})$ from the thermal decomposition $\left(280^{\circ} \mathrm{C}-30 \mathrm{~min}\right.$.) of a mixture of actinides precursor solutions in highly coordinating organic media containing benzyl ether, oleic acid and oleylamine ${ }^{10-12}$. At the opposite of the length scale, the production of uranium oxide spheres, typically in the $100-500 \mu \mathrm{m}$ range, has been reported for a long time from the initial precipitation of precursors through sol-gel processes ${ }^{13,14}$. Protocols based on the impregnation of resin beads by solutions containing actinides and subsequent heat treatment at high temperature were also studied to initiate dustless processes for the elaboration of $\mathrm{AnO}_{2}$ pellets ${ }^{4,15}$.

Conversely, only few studies were dedicated to the fabrication of spherical actinide oxide particles in an intermediate size range, i.e. from about 50 to $2000 \mathrm{~nm}$. Physical methods such as aerosol spray pyrolysis appeared to be suitable for the production of monodisperse particles, as their size is directly controlled by the diameter of the droplets forming the aerosol 5 . Nevertheless, this kind of process requires specific equipment, which might be difficult to implement in nuclear facilities aiming to work with radionuclides of high specific activity. On this basis, simple wet-chemistry routes based on the hydrothermal precipitation of mixtures containing either thorium, uranium(IV) or uranium(VI) in acidic solutions, precipitating agent 
(urea) and shaping agent (PEG, glycerol) were recently considered ${ }^{16-18}$. However, this often yielded porous and/or very small particles (typically from 50 to $250 \mathrm{~nm}$ in diameter). Also, even if Wang et al. reported accurate size tuning during the synthesis of $\mathrm{ThO}_{2}$ nanoparticles ${ }^{19}$, the final diameter remained generally uncontrolled when dealing with $\mathrm{UO}_{2}$ particles.

This study reports a new and simple wet chemistry route to spherical $\mathrm{UO}_{2}$ particles from the initial precipitation of uranium(IV) aspartate and its conversion under hydrothermal conditions. Aspartic acid was chosen as precipitating agent owing to its good complexation properties with regard to actinides ${ }^{20,21}$. Also, it readily decomposes under hydrothermal conditions, mainly through deamination ${ }^{22}$. The aspartate precursor was first characterized, then a multiparametric study of its conversion into uranium dioxide was undertaken, with the aim to accurately control both size and shape of the particles. Finally, the thermal behaviour of the $\mathrm{UO}_{2}$ particles was investigated to evaluate the possible use of the particles as models for the sintering of nuclear fuels or standards in nuclear safeguard analyses. 


\section{Experimental}

Caution! Uranium is an $\alpha$-emitter natural radioelement and as such is considered a health risk. Its use requires appropriate infrastructure and staff training regarding the handling of radioactive materials.

Chemicals. All the reagents used were of analytical-grade and supplied by Sigma-Aldrich, except uranium sources, while deionized water $\left(18.2 \mathrm{M} \Omega . \mathrm{cm}\right.$ at $\left.25^{\circ} \mathrm{C}\right)$ supplied by a Merck Milli- Q apparatus was used to prepare all aqueous solutions. The uranium tetrachloride solution was prepared by dissolving uranium metal chips in concentrated hydrochloric acid. The metal pieces were first rinsed with dichloromethane, acetone and water, washed in $1 \mathrm{M}$ $\mathrm{HCl}$ in order to eliminate possible traces of uranium oxide present at the surface, and finally dissolved in $6 \mathrm{M} \mathrm{HCl}$. High chloride concentration allowed us to maintain the tetravalent oxidation state of uranium in solution for several months ${ }^{23}$. The uranium concentration of the final solution was estimated to $0.52 \pm 0.02 \mathrm{M}\left(4.14 \times 10^{-4} \mathrm{~mol} . \mathrm{g}^{-1}\right)$ by ICP-AES measurements.

Preparation of the samples. The synthesis protocol for spherical $\mathrm{UO}_{2}$ particles is based on the complexation of $\mathrm{U}^{4+}$ by aspartic acid and on the subsequent hydrothermal conversion of the obtained precursor. It was derived from our previous work undertaken on the aspartic $\mathrm{acid} / \mathrm{Th}^{4+}$ system $^{24}$. Aspartic acid $(1-1.5 \mathrm{mmol})$ was first weighted and dissolved in $10 \mathrm{~mL}$ $\mathrm{H}_{2} \mathrm{O}$. The $\mathrm{pH}$ of the resulting solution was raised to 2 by addition of $30 \% \mathrm{NH}_{4} \mathrm{OH}$. The hydrochloric solution containing tetravalent uranium $(0.5 \mathrm{mmol})$ was then added dropwise, while controlling the $\mathrm{pH}$ with ammonia. The mixture of solutions rapidly led to the formation of a greenish precipitate. The concentration of uranium remaining in the supernatant was analysed by Photo-Electron Rejecting Alpha Liquid Scintillation (PERALS) ${ }^{25}$ (Table 1) and revealed quantitative precipitation.

Afterwards, both solid phase and supernatant were transferred into a Teflon-lined autoclave (Parr) and treated hydrothermally at $160^{\circ} \mathrm{C}$ for 1 to 30 hours. For several tests, the reacting media were agitated during hydrothermal treatment using a magnetic stirrer (2Mag MixControl 20). This setup was chosen to be close to the unbaffled stirred tank reactors envisaged for precipitation reactions in nuclear fuel reprocessing industry ${ }^{26}$. Whatever the operating conditions, the autoclave was cooled down overnight before collecting the final precipitate. This latter was separated by centrifugation, washed twice with deionized water and twice with ethanol, and finally dried overnight at $60^{\circ} \mathrm{C}$ in an oven. 
SEM observations. Before the SEM study, the samples were systematically dispersed in ethanol and deposited on a mirror-grade polished aluminium plate. Scanning Electron Microscope (SEM) micrographs were then directly recorded from the as-deposited powders without any additional preparation such as metallization. A FEI Quanta 200 environmental scanning electron microscope, equipped with an Everhart-Thornley Detector (ETD) and a Back-Scattered Electron Detector (BSED) was used to record images with an acceleration voltage of $2 \mathrm{kV}$ under high vacuum conditions.

SEM images were then processed using the ImageJ software ${ }^{27}$ in order to determine the average particle size as well as the size distribution. In this aim, low-magnification (5000x) images were recorded with a resolution of $2048 \times 1768$ pixels, leading to the analysis of populations of at least 300 particles.

PXRD. Powder X-Ray Diffraction (PXRD) diagrams were obtained by means of a Bruker D8 diffractometer equipped with a Lynx-eye detector adopting the reflexion geometry, and using $\mathrm{Cu} \mathrm{K} \alpha_{1,2}$ radiation $(\lambda=1.54184 \AA$ ). PXRD patterns were recorded at room temperature in the $5^{\circ} \leq 2 \theta \leq 100^{\circ}$ range, with a step size of $\Delta(2 \theta)=0.01^{\circ}$ and a total counting time of about 3 hours per sample. In order to avoid any radioactive contamination, the powders were placed in a special sample holder (dome-shaped container with anti-scattering blade) that could generate additional peak at around $6^{\circ}(2 \theta)$.

NMR. MAS NMR measurements were performed on a Bruker Avance III 400 spectrometer, equipped with a $4 \mathrm{~mm}$ MAS probe $1 \mathrm{H} / \mathrm{X}$. Samples were packed into zirconia rotors and spun at $12 \mathrm{kHz}$ at room temperature. ${ }^{13} \mathrm{C}$ spectra were recorded using TMS (liq.) as a reference. ${ }^{13} \mathrm{C}$ CPMAS (Cross Polarization) experiments were performed with a contact time of $2 \mathrm{~ms}$ and a recycle delay of $5 \mathrm{~s}$.

FTIR. Attenuated Total Reflectance Fourier Transform InfraRed (ATR-FTIR) spectra were recorded in the 380-4000 $\mathrm{cm}^{-1}$ range thanks to a Perkin-Elmer FTIR Spectrum 100 device. Powdered samples were deposited at the surface of the single bounce diamond crystal ATR accessory without any prior preparation. The spectra collected in such operating conditions exhibited a resolution lower than $2 \mathrm{~cm}^{-1}$. 
TG-DT Analyses. Thermogravimetric analyses were undertaken thanks to a Setaram Setsys Evolution equipped with a type S thermocouple (Pt / Pt-10\%Rh). After recording a baseline using an empty crucible $(100 \mu \mathrm{L})$, weight loss was measured during a heat treatment up to $1000^{\circ} \mathrm{C}$ with a rate of $5^{\circ} \mathrm{C} \cdot \mathrm{min}^{-1}$ under Ar atmosphere. Moreover, the gaseous species emitted during the heat treatment were identified by the means of a Hiden Analytical QGA analyser using mass spectrometry.

\section{Results and discussion}

\subsection{Characterization of the initial precipitate}

The precipitate rapidly obtained after the addition of uranium(IV) hydrochloric solution to aspartic acid was first characterized through XRD, SEM and ${ }^{13} \mathrm{C}$ NMR. PXRD analysis led to a noisy pattern without any detectable diffraction line, i.e. characteristic of an amorphous and/or nanosized sample. This finding was supported by the SEM micrographs (see Figure S1 supplied as supplementary material) which revealed that the powder was mainly composed of small crystallites of some tenths of nanometers in length, which assembled themselves in larger aggregates. This aggregation appeared to be widely disorganized and did not result in any specific morphology.

In order to identify the chemical nature of the precipitate formed, ${ }^{13} \mathrm{C}$ NMR spectra were recorded and compared to the reference spectrum obtained for aspartic acid (Figure 1). This latter presents two signals at about $175 \mathrm{ppm}$ which were assigned to the carboxylic moieties. Compared to the reference, the spectrum collected for the unknown precipitate appeared dramatically widened, probably as a consequence of the paramagnetic character of $\mathrm{U}^{4+}$ and/or of the lack of sample crystallinity. Nevertheless, this large band occurred between 180 and 190 ppm, meaning that the two components shifted by about 15 ppm in comparison with the aspartic acid reference. This offset then evidences the complexation of uranium by the two carbonyl fragments, leading to the precipitation of uranium(IV) aspartate, probably as a coordination polymer. One must note that this behaviour seems to differ from that observed for thorium, for which only one carbonyl moiety was coordinated to the metal centre, resulting in a molecular specie with the formula $\mathrm{Th}\left(\mathrm{C}_{4} \mathrm{NO}_{4} \mathrm{H}_{6}\right)_{4} \cdot 4 \mathrm{H}_{2} \mathrm{O}{ }^{24}$. On this basis, the

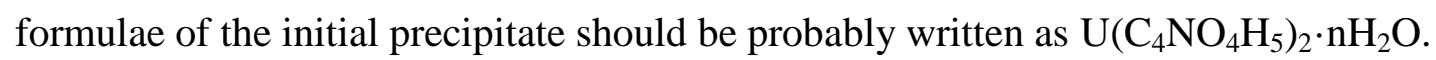


After hydrothermal conversion

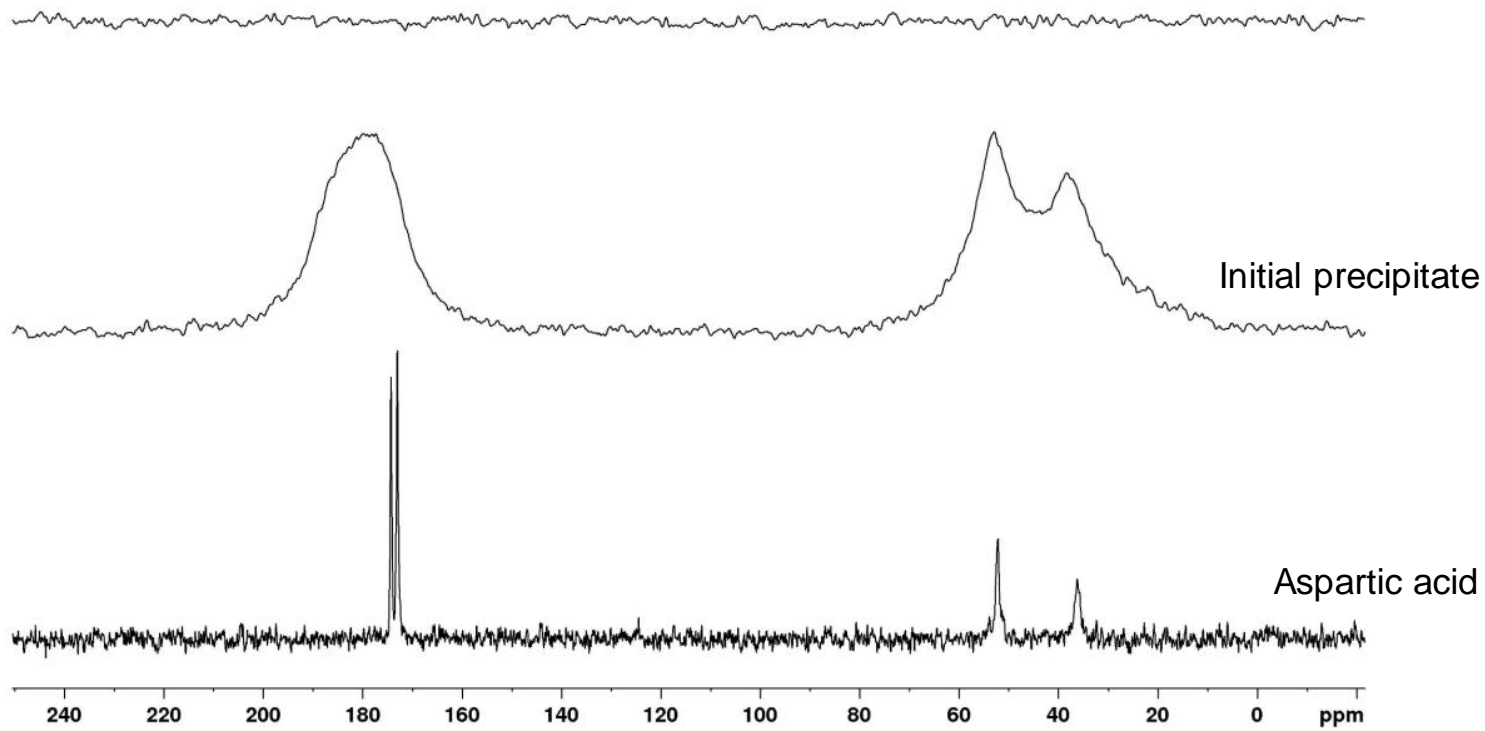

Figure 1. ${ }^{13} \mathrm{C}$ NMR spectra of aspartic acid, of the precipitate obtained when mixing U(IV) hydrochloric solution, and of the sample obtained after hydrothermal conversion $\left(\mathrm{T}=160^{\circ} \mathrm{C}, \mathrm{t}=30 \mathrm{~h}\right)$.

\subsection{Multi-parametric study of hydrothermal conversion}

With the aim to obtain uranium oxide powders and to orientate their morphology, the hydrothermal conversion of the amorphous U(IV) aspartate precursors was undertaken. Recent studies showed that mild hydrothermal conditions induce the decomposition of actinide carboxylates, such as uranium(IV) oxalate, leading to the direct formation of $\mathrm{UO}_{2}$ in solution ${ }^{28}$. As this latter results from the hydrolysis of $\mathrm{U}^{4+}$ after the initial decomposition of the precursor, the $\mathrm{pH}$ of the solution has to be carefully controlled. Preliminary tests were undertaken to determine the optimal acidity of the reacting media. For $\mathrm{pH} \geq 3$, SEM micrographs revealed that the precipitates consist of strongly agglomerated sub-micrometric particles (Figure 2), which probably formed through the fast nucleation of $\mathrm{U}(\mathrm{OH})_{4}$ and further aging as partly amorphous $\mathrm{UO}_{2}$. Indeed, Rai et al. already reported that such a compound readily precipitates at $\mathrm{pH}>2$ at room temperature ${ }^{29}$, while the solubility of 
amorphous $\mathrm{UO}_{2}$ does not sustain important variation up to $300^{\circ} \mathrm{C}{ }^{30}$. For more acidic conditions, i.e. $\mathrm{pH}=1$ and 2 , grains presenting a spherical habit were systematically obtained. However, they appeared to be denser and monodisperse (although significantly smaller) for $\mathrm{pH}=2$. This condition was then retained for the rest of our study. Similarly, we decided to maintain the temperature at $160^{\circ} \mathrm{C}$ in accordance with the protocol originally designed for the thorium counterpart ${ }^{24}$. In order to optimize the operating parameters, a multi-parametric study combining the effects of heating time at $160^{\circ} \mathrm{C}$, of initial metal/ligand ratio and of magnetic stirring was then undertaken.

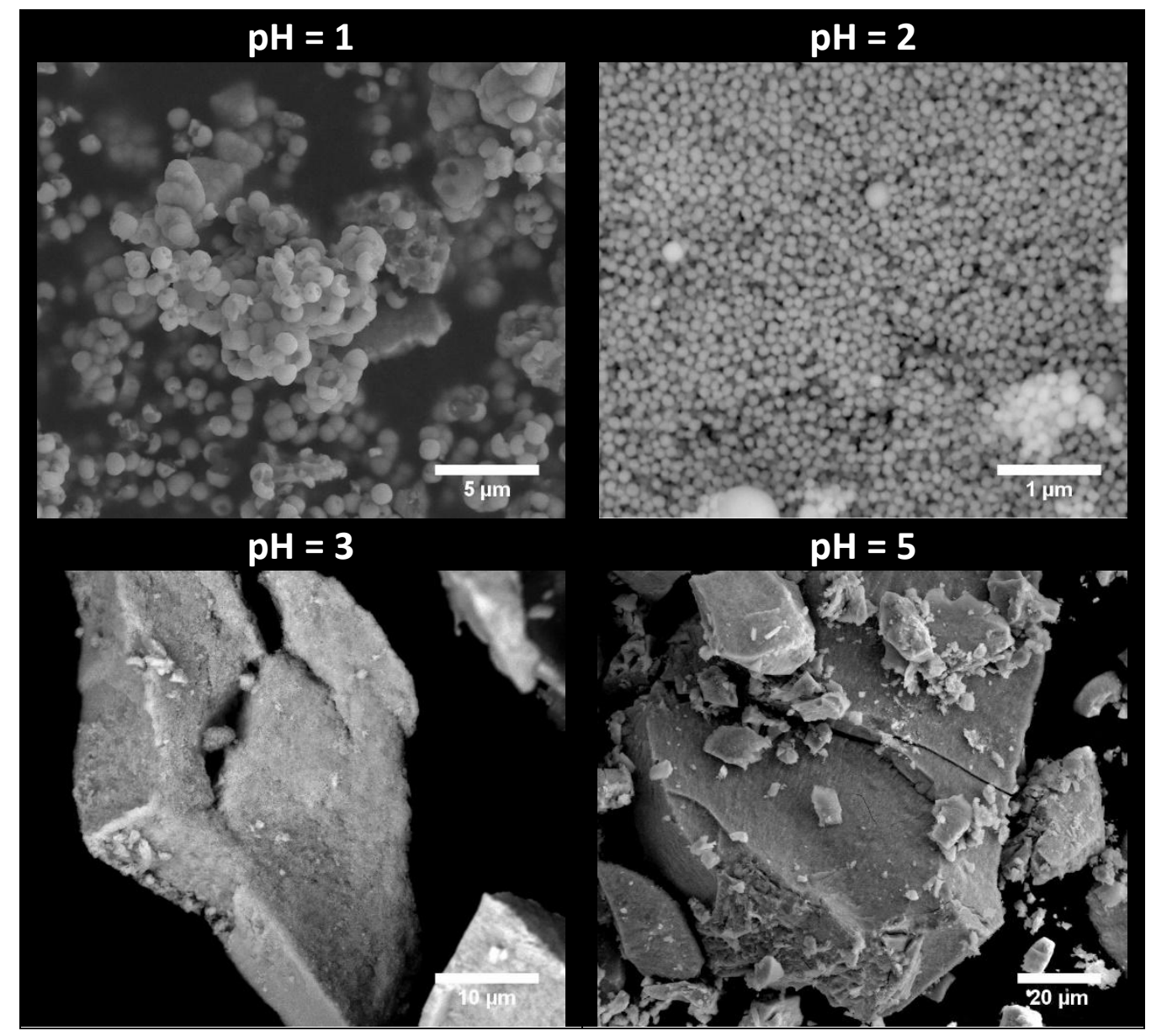

Figure 2. SEM micrographs of the powders obtained after hydrothermal conversion of uranium(IV) aspartate at $160^{\circ} \mathrm{C}$ for different $\mathrm{pH}$. 


\subsubsection{Effect of heating time}

In a first step, the hydrothermal treatment at $160^{\circ} \mathrm{C}$ was extended from 1 to 30 hours. For all the heating times considered, the supernatant was analysed by PERALS ${ }^{25}$ to quantify the concentration of uranium remaining in solution (Table 1). The uranium precipitation yield was found to increase slightly during the first hours of hydrothermal treatment, uranium precipitation becoming quantitative after heating over 24 hours. On this basis, the beginning of the treatment (i.e. up to 6 hours) probably still corresponds to the decomposition of the initial U(IV) aspartate precursor, followed by the partial hydrolysis of the tetravalent uranium in solution. This observation is in very good agreement with the data reported by Faisal et al. concerning the decomposition of aspartic acid under hydrothermal conditions ${ }^{31}$. These authors stated that the main reaction pathway consists in an irreversible deamination yielding malic acid, followed by a possible decarboxylation leading to a mixture of pyruvic and lactic acids :

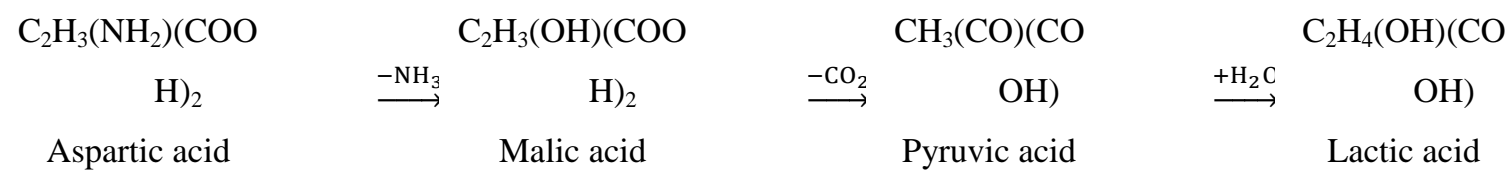

Moreover, based on their determination of kinetic constants at $200^{\circ} \mathrm{C}$ and of the activation energy associated with the decomposition reaction $\left(\mathrm{E}_{\mathrm{A}}=144 \mathrm{~kJ} \cdot \mathrm{mol}^{-1}\right)$, the time required to decompose $99 \%$ of initial aspartic acid can be estimated to be about 5.5 hours at $160^{\circ} \mathrm{C}$. Shorter heating times then should be discarded if one wants to quantitatively recover $\mathrm{U}^{4+}$ from the decomposition of the aspartate precursor in these operating conditions.

Table 1. Determination of the uranium precipitation yield from PERALS analyses for various durations of hydrothermal process $\left(\mathrm{T}=160^{\circ} \mathrm{C}\right)$.

\begin{tabular}{l|l|l|l}
\hline $\begin{array}{l}\text { Heating time } \\
\text { (hours) }\end{array}$ & $\begin{array}{l}\mathbf{n}(\mathbf{U}) \text { initial } \\
(\mathbf{m o l} .)\end{array}$ & $\begin{array}{l}\mathbf{n}(\mathbf{U}) \text { supernatant } \\
(\mathbf{m o l} .)\end{array}$ & $\begin{array}{l}\text { Uranium precipitation yield } \\
(\%)\end{array}$ \\
\hline 0 & $5.55 \times 10^{-4}$ & $(1.1 \pm 0.1) \times 10^{-5}$ & $98 \pm 1$ \\
1 & $4.77 \times 10^{-4}$ & $(6.0 \pm 0.1) \times 10^{-5}$ & $87 \pm 2$ \\
3 & $4.78 \times 10^{-4}$ & $(3.48 \pm 0.07) \times 10^{-5}$ & $93 \pm 2$ \\
6 & $4.78 \times 10^{-4}$ & $(1.68 \pm 0.02) \times 10^{-5}$ & $96 \pm 1$
\end{tabular}




\begin{tabular}{l|l|l|l}
24 & $4.77 \times 10^{-4}$ & $(0.23 \pm 0.01) \times 10^{-5}$ & $99 \pm 2$ \\
30 & $4.78 \times 10^{-4}$ & $(0.34 \pm 0.01) \times 10^{-5}$ & $99 \pm 2$
\end{tabular}

Concomitantly to the increase of the uranium precipitation yield, powder morphology appeared to be strongly modified when increasing the duration of the hydrothermal process. After 1 hour, the morphology was very close to that observed for the aspartate precursor, with a powder composed by sub-micrometric crystallites (Figure 3). This was still found to be the major habit observed between 6 and 24 hours of hydrothermal treatment, but some scarce spherical grains tended to form. After 30 hours, the morphology of the sample drastically changed. The powder appeared to consist of spherical grains with variable sizes, typically ranging from $200 \mathrm{~nm}$ to $1 \mu \mathrm{m}$ in diameter. On this basis, the operating conditions for the hydrothermal treatment were fixed to 30 hours and $\mathrm{T}=160^{\circ} \mathrm{C}$ for all the following experiments.

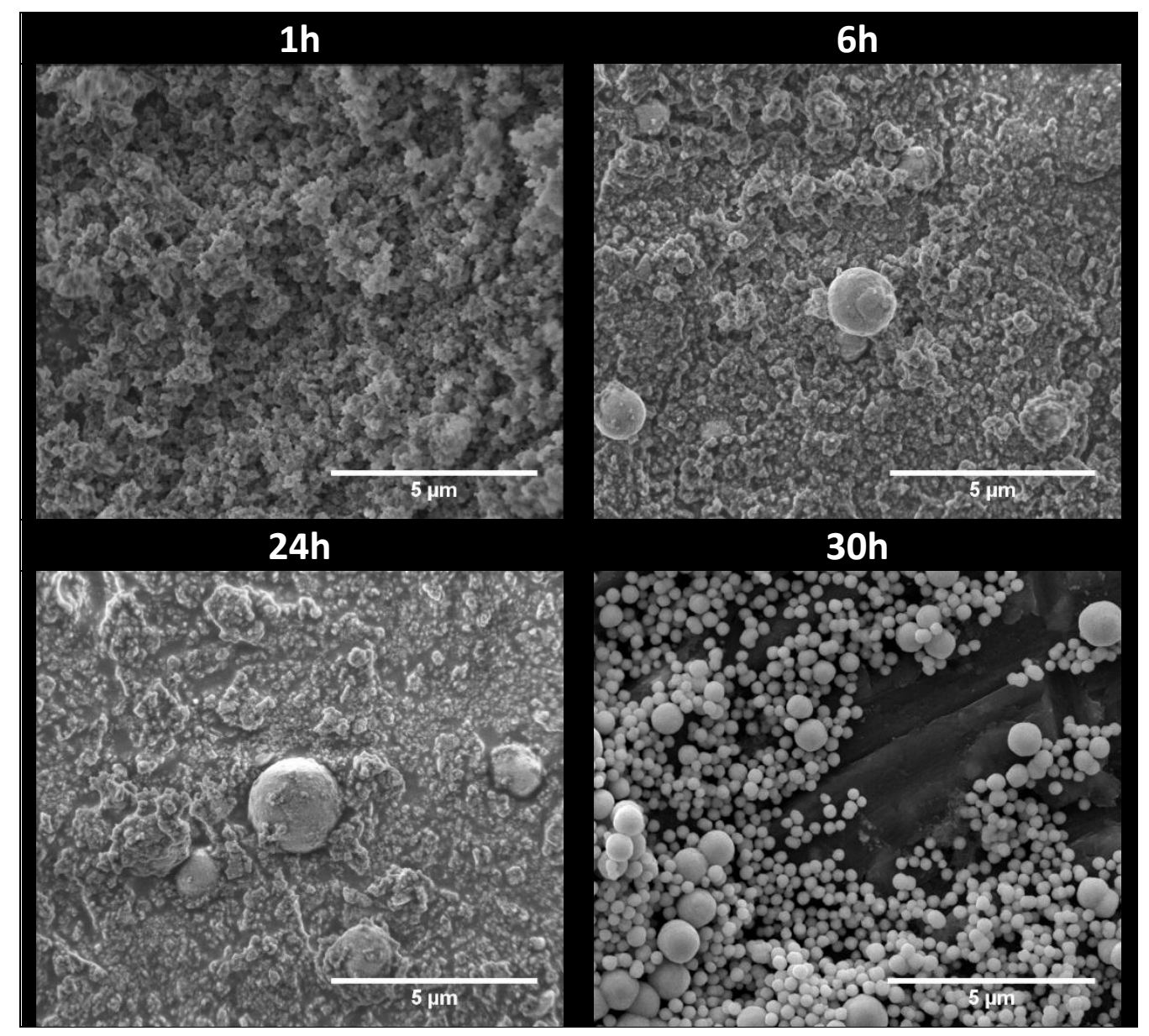

Figure 3. SEM micrographs of the powders obtained after hydrothermal conversion of uranium(IV) aspartate at $160^{\circ} \mathrm{C}$ for different durations. 
The changes observed in the morphology of the samples were also associated to structural modifications. Whatever the conditions chosen, the XRD patterns collected present low-intensity and wide peaks characteristic of poorly crystallized and/or nanosized samples, in good agreement with the SEM observations (Figure 4). Despite the low resolution of the XRD patterns, it was still possible to note an evolution of the structure along the hydrothermal treatment. For samples heated between 1 and 3 hours, the XRD pattern was very close to that previously reported for thorium aspartate ${ }^{24}$. Compared with the NMR data, which rather suggested the initial precipitation of an amorphous uranium(IV) aspartate coordination polymer, this result indicates that a transformation towards a molecular specie probably occurred during the first hours of heat treatment at $160^{\circ} \mathrm{C}$. Under these conditions, short hydrothermal treatment did not allow to convert the precursor into oxide, but only resulted in the transformation and partial crystallization of the initial precipitate. Conversely, after 6 hours of heating at $160^{\circ} \mathrm{C}$ and for longer hydrothermal treatments, the characteristic XRD pattern of nanosized fluorite-type $\mathrm{UO}_{2}$ was evidenced ${ }^{32}$ while the peaks of the U(IV) aspartate were no longer observed. This indicates full conversion in these operating conditions and again appears in good agreement with previous studies dedicated to aspartic acid decomposition under hydrothermal conditions ${ }^{31}$. Moreover, the width of the XRD lines was not significantly modified over the time, meaning that the average crystallite size remained almost unchanged. The spherical particles observed after 30 hours of hydrothermal processing are thus formed by smaller entities, resulting in a hierarchical structure ${ }^{16}$.

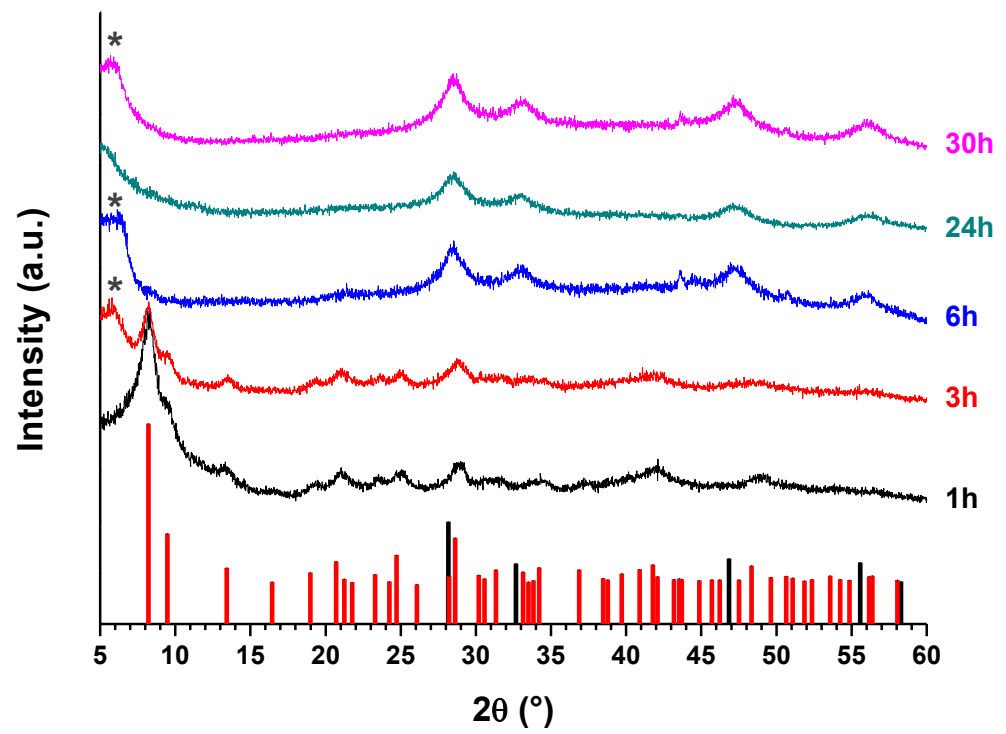

Figure 4. XRD patterns of the samples obtained after hydrothermal conversion of uranium(IV) aspartate at $160^{\circ} \mathrm{C}$ for various durations. Diffraction lines of 
thorium aspartate (red) ${ }^{24}$ and $\mathrm{UO}_{2}$ (black, ICDD \#01-071-4823) are supplied for comparison. * symbols indicate the signal due to anti-contamination domeshaped container.

Complementarily, the FTIR spectrum of the sample heated for 30 hours revealed numerous vibration bands evidencing the presence of residual organics at the surface and/or within the $\mathrm{UO}_{2}$ particles (Figure S2). Also, the comparison to the reference spectra of aspartic acid and thorium aspartate, already discussed in our previous work ${ }^{24}$, showed the absence of vibration bands at around 1475 and $3120 \mathrm{~cm}^{-1}$, which are characteristic of the amine function, and were reported in the literature for uranium(IV)-aspartate complexes ${ }^{33}$. This feature is in good agreement with the reaction path previously described for the decomposition of aspartic acid under hydrothermal conditions ${ }^{31}$, during which deamination is the predominant reaction. On this basis, the organics remaining in the sample are probably dicarboxylic acids resulting from the decomposition of aspartic acid, i.e. malic, pyruvic and/or lactic acid. This hypothesis is corroborated by the existence of large vibration bands at about 1400 and $1600 \mathrm{~cm}^{-1}$, which can be assigned to carboxylic acids. At the same time, ${ }^{13} \mathrm{C}$ NMR spectra did not show any signal (Figure 1), possibly due to limited amounts of different organic species still surrounding the $\mathrm{UO}_{2}$ sample after the conversion of the uranium(IV) aspartate.

\subsubsection{Effect of uranium / aspartic acid stoichiometry}

As the organics resulting from the hydrothermal decomposition of the uranium(IV) aspartate precursor could play a role in the oxide's final morphology, the metal / ligand molar ratio (i.e. uranium / aspartic acid molar ratio) in the initial reacting media was varied in order to evaluate the influence on particle shape and size distribution. First, hydrothermal treatment of the hydrochloric solution of U(IV) was performed at $\mathrm{pH}=2$ without any addition of aspartic acid. In such operating conditions, a small amount of precipitate was obtained after heating for 30 hours at $160^{\circ} \mathrm{C}$. It had wide XRD peak characteristics of the $\mathrm{UO}_{2}$ fluorite-type structure (Figure S3), confirming that the hydrolysis of $\mathrm{U}^{4+}$ was the key-step in the formation of an oxide precipitate. Nevertheless, the powder appeared to be composed of very small grains (Figure 5), comparable to the nanoparticles obtained from synthesis via precipitation of hydroxides ${ }^{32}$. 


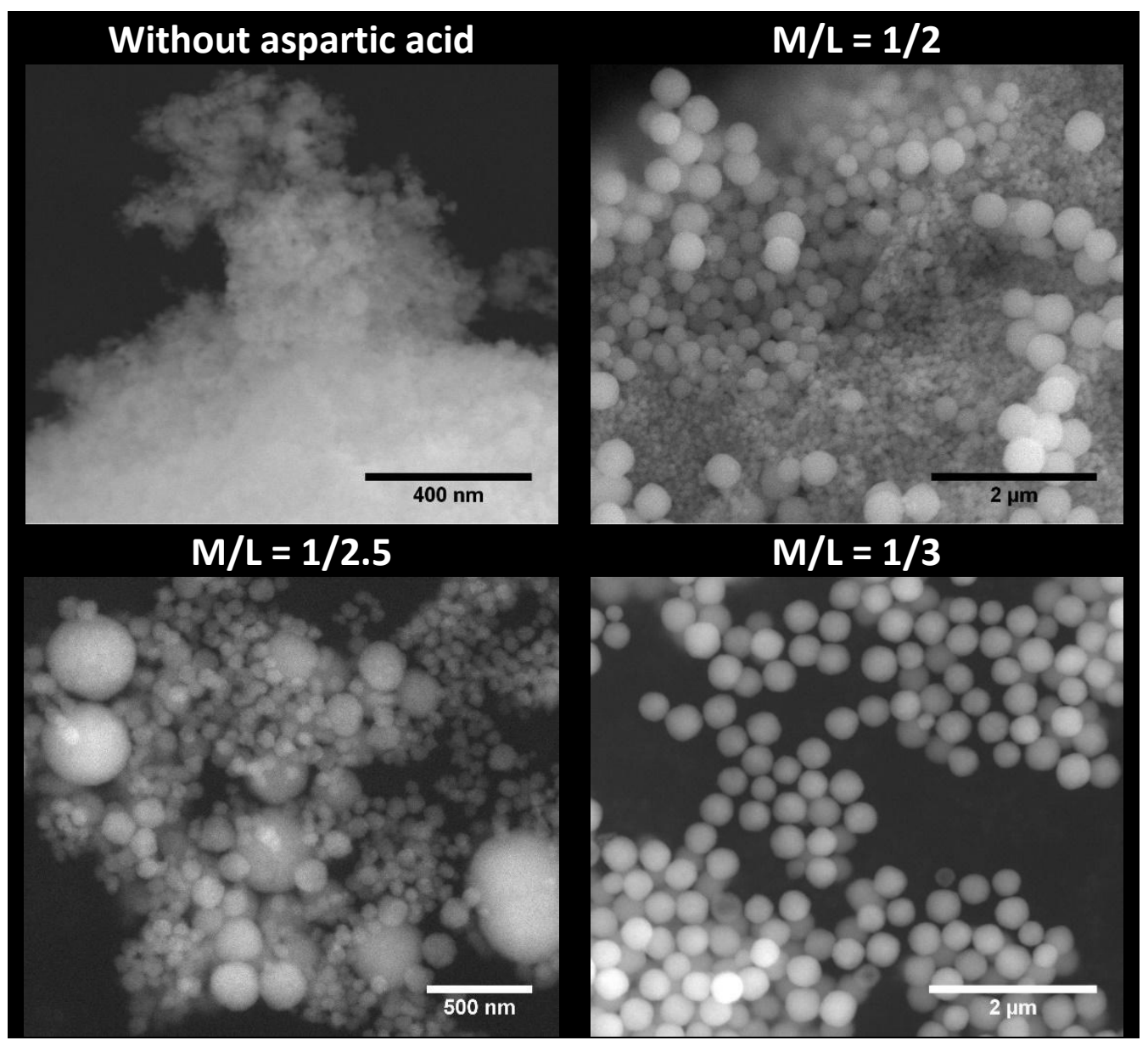

Figure 5. SEM micrographs of the powders obtained after hydrothermal conversion of uranium(IV) aspartate $\left(\mathrm{T}=160^{\circ} \mathrm{C} ; \mathrm{t}=30\right.$ hours $)$ for different metal / ligand ratios.

On the other hand, the introduction of aspartic acid in the reactant mixture, leading to the formation of uranium(IV) aspartate precursor, was systematically associated with the formation of spherical $\mathrm{UO}_{2}$ particles whatever the initial content considered. The residual organic molecules detected in the final oxide particles then probably act as stabilizing agent in the orientation of the sample's morphology towards spheres. Nevertheless, the M/L molar ratio appeared to strongly impact the size distribution of the particles. Indeed, for stoichiometric conditions (i.e. $\mathrm{M} / \mathrm{L}=1 / 2$, based on the initial precipitation of $\left.\mathrm{U}\left(\mathrm{C}_{4} \mathrm{NO}_{4} \mathrm{H}_{5}\right)_{2} \cdot \mathrm{nH}_{2} \mathrm{O}\right)$ and for an excess of $25 \%(\mathrm{M} / \mathrm{L}=1 / 2.5)$, the powder was found to be polydisperse. The powders were composed of a large population of small particles (typically 
between 20 and $150 \mathrm{~nm}$ in diameter) but included some larger spheres up to $700 \mathrm{~nm}$ in diameter. These latter do not account for a large number of particles but represent the main part of the volume (see Figure $\mathbf{S 4}$ supplied as supplementary material). On the other hand, an excess of $50 \%$ in aspartic acid (i.e. $\mathrm{M} / \mathrm{L}=1 / 3$ ) led to a very homogeneous powder. The statistical analysis of the particles showed that the size distribution basically follows a Gaussian law, associated to an average diameter of about $380 \mathrm{~nm}$, and a FWHM of about 60 $\mathrm{nm}$. Owing to a dispersion less than $\pm 10 \%$, the powder can be considered as monodisperse. One can also note that increasing the initial excess in aspartic acid increases the average diameter of the main particle population, typically from around $100 \mathrm{~nm}$ for stoichiometric conditions to about $400 \mathrm{~nm}$ for $50 \%$ excess. On this basis, a molar ratio of $1 / 3$ between uranium(IV) and aspartic acid was considered for the rest of the study in order to recover samples with an homogenous particle size.

\subsubsection{Effect of the magnetic stirring}

In a last step, magnetic stirring was applied during the hydrothermal treatment with the aim to drive the aggregation of the crystallites towards spherical particles, and to get an accurate control over the final size of the particles. In order to accurately quantify the effects of stirring through a dimensionless number, and characterize the flow in the reactor as laminar or turbulent, the impeller Reynolds number (derived from the conventional Reynolds number used to describe flow in pipes) was determined for each stirring speed studied in the range 200-1100 rpm as follows :

$\operatorname{Re}_{\mathrm{a}}=\frac{\mathbf{N} \times \mathbf{D}^{2}}{v}$

Where $\mathrm{N}$ is the impeller (stirrer bar) rotation speed, $\mathrm{D}$ the stirrer bar length and $v$ the kinematic viscosity. Herein, we assimilated the liquid media to pure water and extracted the viscosity value from the study of Deguchi et al. with $v \approx 1.8 \times 10^{-7} \mathrm{~m}^{2} \cdot \mathrm{s}^{-1}$ at $160^{\circ} \mathrm{C}{ }^{34}$. The stirrer bar length $(12 \mathrm{~mm})$ was chosen to be about half the diameter of the reactor $(25 \mathrm{~mm})$, in order to create two mixing zones, i.e. free and forced vortexes, as described by Bertrand et al. 35

On this basis, smooth stirring up to $\mathrm{N} \approx 200 \mathrm{rpm}$ corresponds to $\mathrm{Re}_{\mathrm{a}}<2000$ characteristic of a laminar flow. In this case, the particles size increased from about $400 \mathrm{~nm}$ (no stirring) to $1200 \mathrm{~nm}$ (Figure 6a, selected SEM micrographs provided as supplementary material in Figure S5), meaning that the establishment of a laminar flow in the reactor likely acted in favour of the agglomeration of the elementary crystallites. Between 200 and $800 \mathrm{rpm}$ 
(i.e. $2000<\mathrm{Re}_{\mathrm{a}}<10000$ ), the average particles diameter was found to stabilize between 1.5 and $2 \mu \mathrm{m}$. However, the size distribution appeared to be very wide, meaning that polydisperse powders were obtained due to the establishment of a transition regime between laminar and turbulent flows. Finally, higher agitation speeds led to $\operatorname{Re}_{\mathrm{a}}>10^{4}$, characteristic of turbulent flow. In this case, a clear linear relationship was established between $\mathrm{Re}_{\mathrm{a}}$ (stirring speed) and the average diameter of the spherical $\mathrm{UO}_{2}$ particles (Figure $6 \mathbf{b}$ ). Indeed, the size of the particles was found to decrease from around $2500 \mathrm{~nm}$ to $400 \mathrm{~nm}$ when the stirring speed increased in the $900-1100 \mathrm{rpm}$ range. In this case, the interactive force assembling the crystallites as spherical particles was surpassed by the turbulent shear stress. Growth of the particles was then hindered even though aggregation of the crystallites is favoured by the increase of agitation speed ${ }^{36}$. Lastly, one must note that three different batches were prepared at $950 \mathrm{rpm}\left(\operatorname{Re}_{\mathrm{a}}=12000\right)$ to verify the reproducibility of the process developed. In these conditions, all the powders exhibited very similar average particle diameters (i.e. $1340 \pm 65$, $1390 \pm 80$ and $1410 \pm 50 \mathrm{~nm}$ ) which confirms the accuracy of the size control provided by the magnetic stirring during the hydrothermal conversion.

(a)

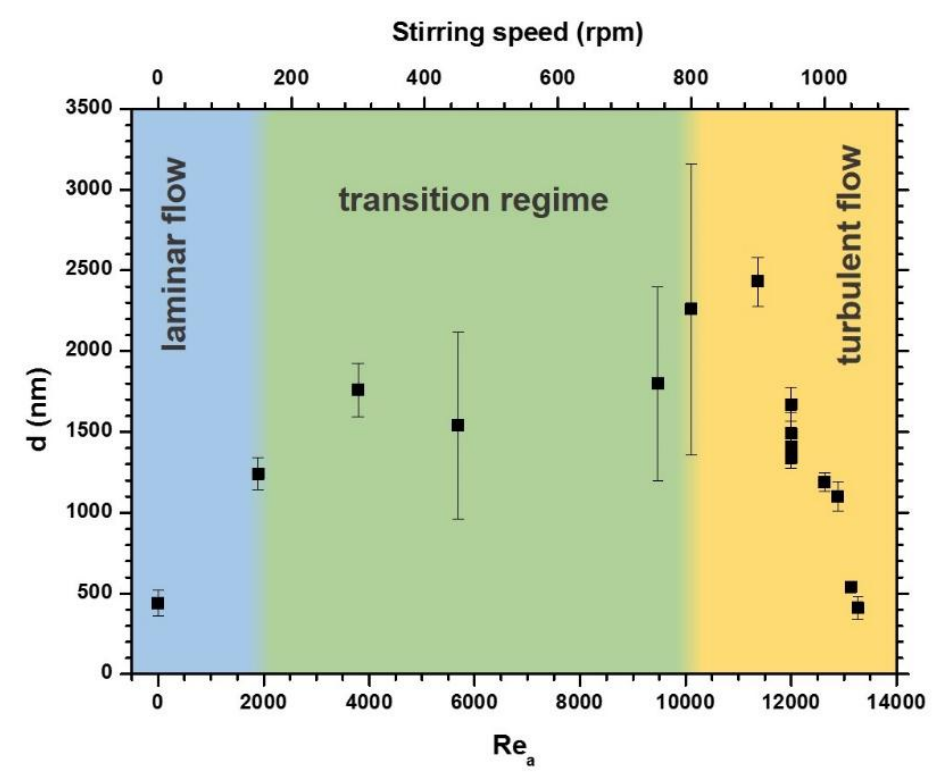


(b)

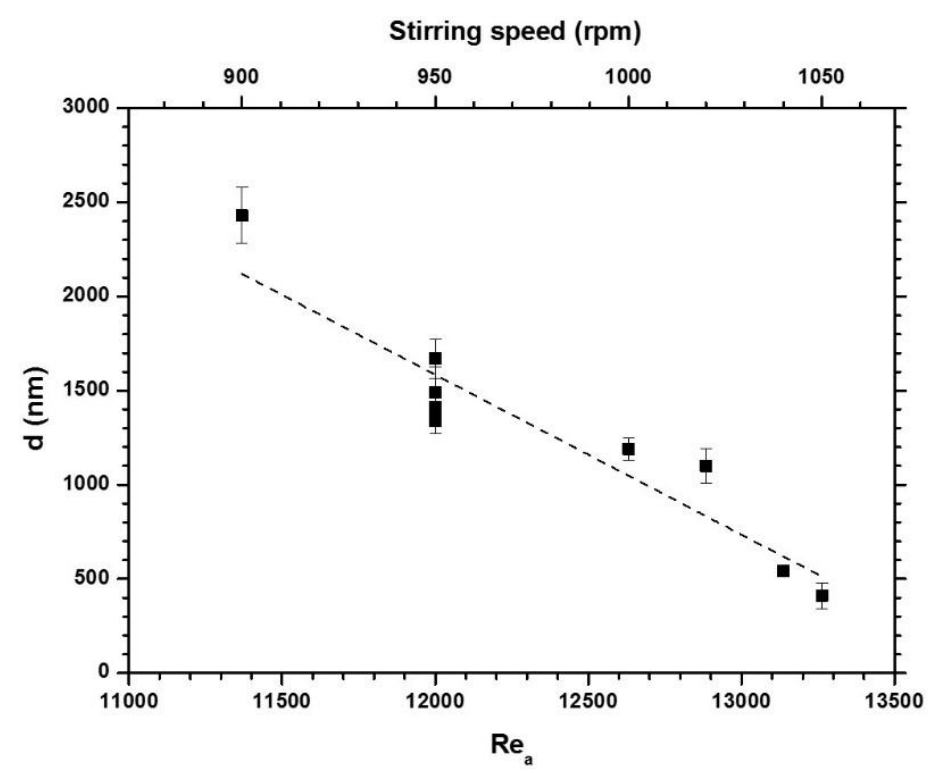

Figure 6. Variation of the average diameter of $\mathrm{UO}_{2}$ spherical particles versus the impeller Reynolds number and corresponding magnetic stirrer speed (a), and focus on the turbulent flow region (b) $\left(T=160^{\circ} \mathrm{C} ; \mathrm{t}=30\right.$ hours; $\left.\mathrm{M} / \mathrm{L}=1 / 3\right)$.

\subsection{Thermal behaviour of $\mathrm{UO}_{2}$ particles}

As the spherical $\mathrm{UO}_{2}$ particles prepared following the protocol detailed previously still exhibit traces of organics and/or water, an additional heating step was envisaged to recover pure $\mathrm{UO}_{2}$. The thermal behaviour was then investigated under argon atmosphere through TG analysis and SEM observations. The thermogram displayed in Figure $\mathbf{7}$ shows that the weight loss mainly occurred through two distinct steps. Based on MS measurements, the gases eliminated were associated to the dehydration of the sample, on the one hand, and to the thermal decomposition of the residual organics, on the other. The first one, observed between 100 and $200^{\circ} \mathrm{C}$, corresponds to the elimination of 0.2 water molecule per formula unit. This low hydration is in good agreement with the hypothesis of formation of $\mathrm{U}(\mathrm{OH})_{4}$ followed by aging into $\mathrm{UO}_{2} \cdot \mathrm{nH}_{2} \mathrm{O}$. Indeed, the number of water molecules reported in the literature for such compounds, which can also be written as $\mathrm{UO}_{(2-\mathrm{n})}(\mathrm{OH})_{2 \mathrm{n}}$ hydrated oxyhydroxyde, is generally between 0 and $2^{30}$. 


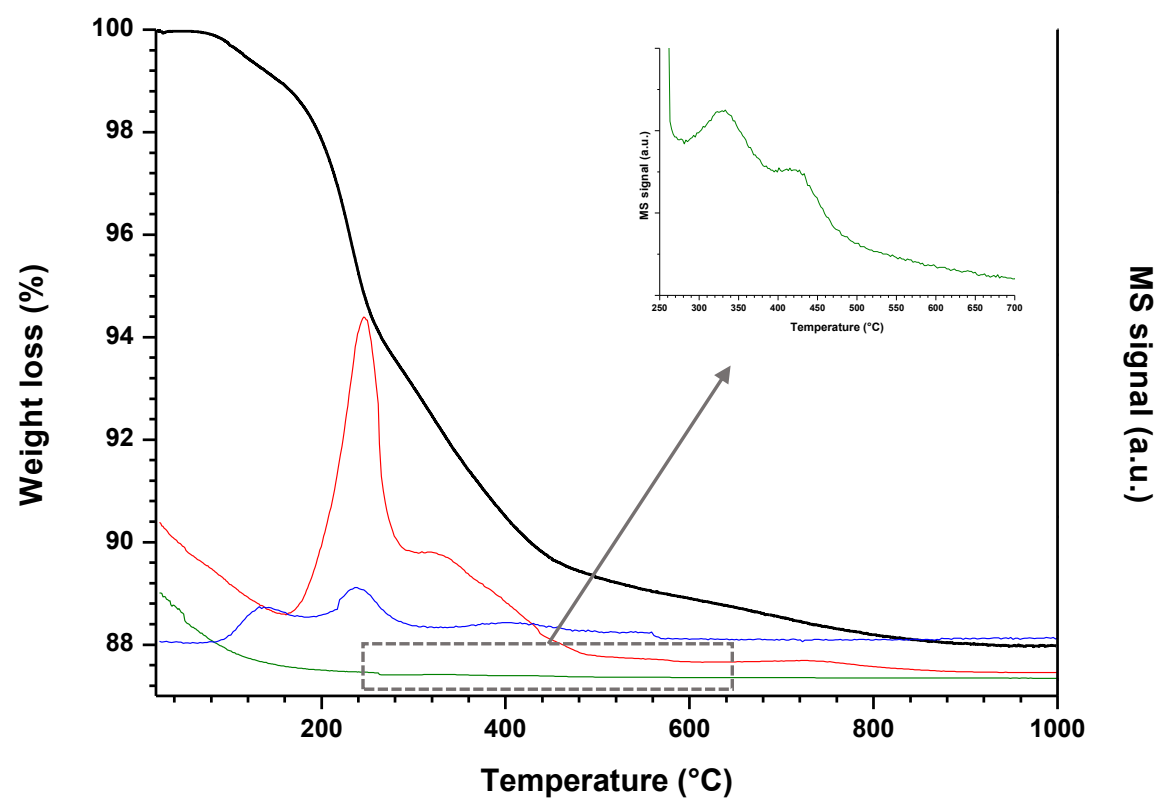

Figure 7. TG analyses and associated MS signals of water (blue), $\mathrm{CO}+\mathrm{CO}_{2}$ (red) and $\mathrm{NO}+\mathrm{NO}_{2}$ (green) for $\mathrm{UO}_{2}$ spherical particles prepared after hydrothermal conversion of uranium(IV) aspartate $\left(T=160^{\circ} \mathrm{C} ; \mathrm{t}=30\right.$ hours; $\left.\mathrm{M} / \mathrm{L}=1 / 3\right)$.

The second weight loss recorded between 200 and $400^{\circ} \mathrm{C}$, mainly correlated with the emission of $\mathrm{H}_{2} \mathrm{O}, \mathrm{CO}$ and $\mathrm{CO}_{2}$, is by far the most important (around $10 \%$ of the initial mass) and indicates the presence of residual organics in the system. Moreover, a slight change in the slope shows that the decomposition occurred in two steps, which can be associated to the presence of different organic molecules within the sample, and/or to the existence of intermediates during their thermal decomposition. For example, such behaviour was observed during the decomposition of actinide oxalates, with the formation of carbonate or oxocarbonate compounds ${ }^{37,38}$. Additionally, only very limited amounts of $\mathrm{NO}$ and $\mathrm{NO}_{2}$ were detected during the thermal decomposition of the organic part of the solid, which confirms that it is mainly composed of carboxylic acid resulting from the deamination of the initial aspartate groups.

Finally, it is worth noting that a slight weight loss signal was recorded between 500 and $1000^{\circ} \mathrm{C}$, and associated with the detection of small amounts of $\mathrm{CO}$ and $\mathrm{CO}_{2}$, which could be assigned to the elimination of residual carbon in the sample. Indeed, the thermal decomposition of $\mathrm{MO}_{2}$ precursors, including carboxylates such as oxalates, was systematically associated with the presence of amorphous carbon within the final oxides ${ }^{39,40}$. On this basis, it can be concluded that residual organics are not only present at the surface of 
the spherical $\mathrm{UO}_{2}$ particles where they act as shaping agent, but also within the spheres themselves, potentially adsorbed to the elementary crystallites. Nevertheless, the amount of carbon still present in the samples remains low at this stage, and one can consider that pure $\mathrm{UO}_{2}$ was obtained after heating above $600^{\circ} \mathrm{C}$.

As heating the samples is required to recover anhydrous and organic-free $\mathrm{UO}_{2}$ samples, SEM observations were undertaken on powders heated between 600 and $1200^{\circ} \mathrm{C}$ to study potential evolution in morphology (Figure 8). At $600^{\circ} \mathrm{C}$, despite the loss of water molecules and residual organics which account for about $10 \%$ of the initial weight, the spherical morphology of the particles is maintained. The more likely hypothesis is that both $\mathrm{H}_{2} \mathrm{O}$, CO and $\mathrm{CO}_{2}$ gaseous molecules can be evacuated through small pores remaining between the crystallites constituting the aggregates. Indeed, such mesoporosity has been previously identified in analogous systems such as $\mathrm{CeO}_{2}$ and $\mathrm{ThO}_{2}$ microspheres ${ }^{9,41}$.

In a second step, the morphology of the aggregates slightly evolved up to $1000^{\circ} \mathrm{C}$ as a consequence of crystallite growth within the particles. Once again, this two-step behaviour is in good agreement with data reported in the literature. Particularly, Claparede et al. ${ }^{42,43}$ showed that for $\mathrm{MO}_{2}$ fluorite-type compounds (with $\mathrm{M}=\mathrm{Ce}$ and/or $\mathrm{Th}$ ), the average crystallite size first slowly increases between room temperature and $700^{\circ} \mathrm{C}$ through defect elimination. Conversely, the solid state diffusion processes involved in crystallite growth are triggered by higher temperature, resulting in a rapid increase of average size. In this study, such a phenomenon led to a blackberry-like morphology with crystallites of about 20-50 nm at the surface of the spheres. Finally, the spherical morphology of the particles was kept even after heating the powders up to $1200^{\circ} \mathrm{C}$. Nevertheless, such a high temperature led to initiate sintering phenomena, as attested by the observation of numerous necks between the particles on the SEM micrograph. On this basis, if one wants to recover individual particles, for example for analytical purposes, heating above $800 / 1000^{\circ} \mathrm{C}$ should be avoided to limit coalescence. 


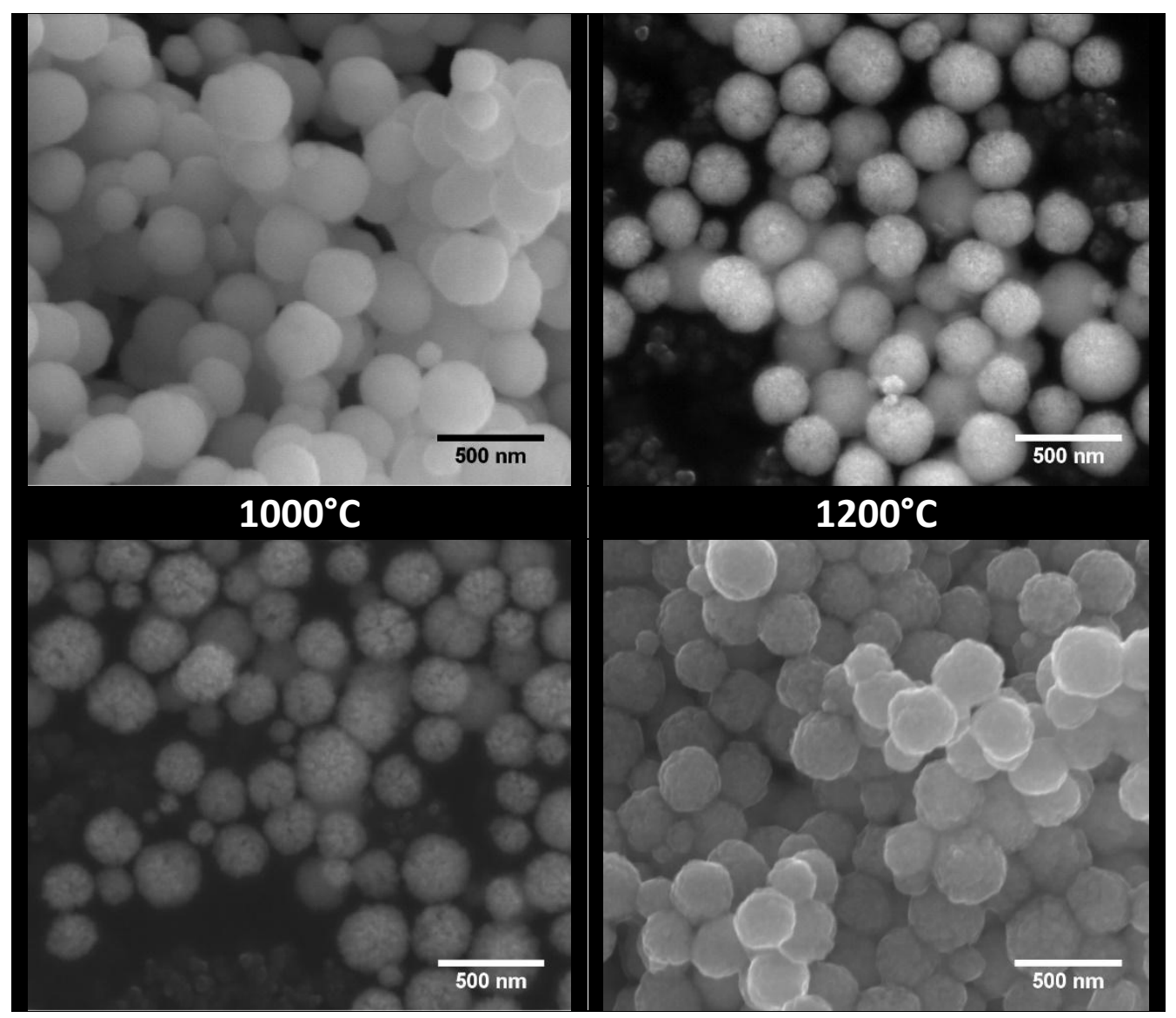

Figure 8. SEM observations of the $\mathrm{UO}_{2}$ spherical particles prepared after hydrothermal conversion of uranium(IV) aspartate $\left(\mathrm{T}=160^{\circ} \mathrm{C} ; \mathrm{t}=30\right.$ hours; $\left.\mathrm{M} / \mathrm{L}=1 / 3\right)$ then heating between 600 and $1200^{\circ} \mathrm{C}$ under argon atmosphere. 


\section{Conclusion}

An easy wet chemistry route to prepare submicrometric spherical $\mathrm{UO}_{2}$ particles was designed through the hydrothermal conversion of uranium(IV) aspartate. An initial amorphous precursor was obtained by mixing hydrochloric solution containing tetravalent uranium with aspartic acid, resulting in quantitative precipitation. The conversion towards $\mathrm{UO}_{2}$ precipitates was then operated via heat treatment under mild hydrothermal conditions at $\mathrm{T}=160^{\circ} \mathrm{C}$. A multiparametric study then allowed us to specify the operating conditions leading to monodisperse and size-controlled particles. Hydrothermal treatment of 6 hours was found necessary to completely convert the precursor into dioxide. Moreover, additional heating up to 30 hours appeared to be mandatory in order to recover only spherical particles. Their size distribution appeared to be driven by the amount of organics in the solution, i.e. by the initial uranium/aspartic acid molar ratio. On this basis, a minimal excess of $50 \%$ in ligand $(\mathrm{M} / \mathrm{L}=1 / 3)$ was required to obtain monodispere powders, with a typical variation of about $\pm 10 \%$ on the average diameter. Finally, it was possible to control particle size by applying magnetic stirring during the hydrothermal treatment. In a turbulent flow regime, i.e. impeller Reynolds number above $10^{4}$, a linear variation of the particle diameter versus the stirring speed was observed, with size ranging from $400 \mathrm{~nm}$ (1050 rpm) to $2500 \mathrm{~nm}$ (900 rpm), which paves the way to applications of such materials in various scientific areas. Also, the protocol was found to be robust and reproducible, with only very limited size variation from one batch to another.

Such one-pot wet chemistry route appears to be very promising for the production of spherical $\mathrm{UO}_{2}$ particles and can be simply implemented in any nuclear chemistry lab. Additional experiments are now under progress to extend this methodology to other systems of interest, including mixed-oxides such as $(\mathrm{U}, \mathrm{Th}) \mathrm{O}_{2},(\mathrm{U}, \mathrm{Ce}) \mathrm{O}_{2}$ and $\left(\mathrm{U}, \mathrm{Ln}^{\mathrm{III}}\right) \mathrm{O}_{2-\mathrm{x}}$.

\section{Acknowledgements}

Authors are grateful to P. Vilbert, M. Ibrahim Osmane and S. Parrès-Maynadié for their help during the preparation of the samples and the acquisition of NMR spectra, respectively. They would also like to thank the Materials Federative Project included in the NEEDS program (Nucléaire, Energie, Environnement, Déchets, Société) of CNRS for its continuous financial support. This study received funding from the GENIORS project (H2020 Euratom Research and Innovation Programme under grant agreement $\mathrm{n}^{\circ} 755171$ ). 


\section{References}

1. Pradhan, M.; Sarkar, S.; Sinha, A. K.; Basu, M.; Pal, T.: Morphology controlled uranium oxide hydroxide hydrate for catalysis, luminescence and SERS studies, Crystengcomm 2011, 13, 2878-2889.

2. Kelly, J. E.: Generation IV International Forum: A decade of progress through international cooperation, Prog Nucl Energ 2014, 77, 240-246.

3. Santana, H. H. S.; Maier, G.; Rodenas, J.: Flowability analysis of uranium dioxide powder at different temperatures containing different lubricants, Appl Radiat Isot 2011, 69, 1162-1164.

4. Remy, E.; Picart, S.; Grandjean, S.; Delahaye, T.; Herlet, N.; Allegri, P.; Dugne, O.; Podor, R.; Clavier, N.; Blanchart, P.; Ayral, A.: Calcined resin microsphere pelletization (CRMP): A novel process for sintered metallic oxide pellets, J Eur Ceram Soc 2012, 32, 3199-3209.

5. Middendorp, R.; Durr, M.; Knott, A.; Pointurier, F.; Sanchez, D. F.; Samson, V.; Grolimund, D.: Characterization of the Aerosol-Based Synthesis of Uranium Particles as a Potential Reference Material for Microanalytical Methods, Anal Chem 2017, 89, 4721-4728.

6. Middendorp, R.; Durr, M.; Bosbach, D.: The stability of uranium microspheres for future application as reference standard in analytical measurements, Procedia Chem 2016, 21, 285-292.

7. Wang, Q.; Li, G. D.; Xu, S.; Li, J. X.; Chen, J. S.: Synthesis of uranium oxide nanoparticles and their catalytic performance for benzyl alcohol conversion to benzaldehyde, J Mater Chem 2008, 18, 1146-1152.

8. Nkou Bouala, G. I.; Clavier, N.; Martin, S.; Lechelle, J.; Favrichon, J.; Brau, H. P.; Dacheux, N.; Podor, R.: From in Situ HT-ESEM Observations to Simulation: How Does Polycrystallinity Affects the Sintering of $\mathrm{CeO}_{2}$ Microspheres?, J Phys Chem C 2016, 120, 386-395.

9. Nkou Bouala, G. I.; Clavier, N.; Léchelle, J.; Monnier, J.; Ricolleau, C.; Dacheux, N.; Podor, R.: High-temperature electron microscopy study of $\mathrm{ThO}_{2}$ microspheres sintering, J Eur Ceram Soc 2016, 37, 727-738.

10. Hudry, D.; Apostolidis, C.; Walter, O.; Gouder, T.; Courtois, E.; Kubel, C.; Meyer, D.: Non-aqueous Synthesis of Isotropic and Anisotropic Actinide Oxide Nanocrystals, Chem-Eur J 2012, 18, 8283-8287.

11. Hudry, D.; Apostolidis, C.; Walter, O.; Gouder, T.; Janssen, A.; Courtois, E.; Kubel, C.; Meyer, D.: Synthesis of transuranium-based nanocrystals via the thermal decomposition of actinyl nitrates, Rsc Advances 2013, 3, 18271-18274.

12. Hudry, D.; Apostolidis, C.; Walter, O.; Janssen, A.; Manara, D.; Griveau, J. C.; Colineau, E.; Vitova, T.; Prussmann, T.; Wang, D.; Kubel, C.; Meyer, D.: Ultra-Small Plutonium Oxide Nanocrystals: An Innovative Material in Plutonium Science, ChemEur J 2014, 20, 10431-10438.

13. Daniels, H.; Neumeier, S.; Bukaemskiy, A. A.; Modolo, G.; Bosbach, D.: Fabrication of oxidic uranium-neodymium microspheres by internal gelation, Prog Nucl Energ 2012, 57, 106-110.

14. Kumar, A.; Radhakrishna, J.; Kumar, N.; Pai, R. V.; Dehadrai, J. V.; Deb, A. C.; Mukerjee, S. K.: Studies on preparation of $\left(\mathrm{U}_{0.47} \mathrm{Pu}_{0.53}\right) \mathrm{O}_{2}$ microspheres by internal gelation process, $\mathrm{J}$ Nucl Mater 2013, 434, 162-169. 
15. Picart, S.; Parant, P.; Caisso, M.; Remy, E.; Mokhtari, H.; Jobelin, I.; Bayle, J. P.; Martin, C. L.; Blanchart, P.; Ayral, A.; Delahaye, T.: Porous metal oxide microspheres from ion exchange resin, Eur Phys J-Spec Top 2015, 224, 1675-1687.

16. Nkou Bouala, G. I.; Clavier, N.; Podor, R.; Cambedouzou, J.; Mesbah, A.; Brau, H. P.; Léchelle, J.; Dacheux, N.: Preparation and characterisation of uranium oxides with spherical shapes and hierarchical structures, Crystengcomm 2014, 16, 6944-6954.

17. Wang, L.; Zhao, R.; Wang, C. Z.; Yuan, L. Y.; Gu, Z. J.; Xiao, C. L.; Wang, S. A.; Wang, X. W.; Zhao, Y. L.; Chai, Z. F.; Shi, W. Q.: Template-Free Synthesis and Mechanistic Study of Porous Three-Dimensional Hierarchical Uranium-Containing and Uranium Oxide Microspheres, Chem-Eur J 2014, 20, 12655-12662.

18. Zhao, R.; Wang, L.; Gu, Z. J.; Yuan, L. Y.; Xiao, C. L.; Zhao, Y. L.; Chai, Z. F.; Shi, W. Q.: A facile additive-free method for tunable fabrication of $\mathrm{UO}_{2}$ and $\mathrm{U}_{3} \mathrm{O}_{8}$ nanoparticles in aqueous solution, Crystengcomm 2014, 16, 2645-2651.

19. Wang, L.; Zhao, R.; Wang, X. W.; Mei, L.; Yuan, L. Y.; Wang, S. A.; Chai, Z. F.; Shi, W. Q.: Size-tunable synthesis of monodisperse thorium dioxide nanoparticles and their performance on the adsorption of dye molecules, Crystengcomm 2014, 16, 1046910475.

20. Andres, Y.; MacCordick, H. J.; Hubert, J. C.: Selective biosorption of thorium ions by an immobilized mycobacterial biomass, Appl Microbiol Biotechnol 1995, 44, 271-276.

21. Humelnicu, D.; Drochioiu, G.; Popa, K.: Bioaccumulation of thorium and uranyl ions on Saccharomyces cerevisiae, J Radioanal Nucl Chem 2004, 260, 291-293.

22. Sato, N.; Quitain, A. T.; Kang, K.; Daimon, H.; Fujie, K.: Reaction kinetics of amino acid decomposition in high-temperature and high-pressure water, Ind Eng Chem Res 2004, 43, 3217-3222.

23. Dacheux, N.; Brandel, V.; Genet, M.: Synthesis and Properties of Uranium Chloride Phosphate Tetrahydrate - $\mathrm{UClPO}_{4} \cdot 4 \mathrm{H}_{2} \mathrm{O}$, New J Chem 1995, 19, 1029-1036.

24. Clavier, N.; Maynadie, J.; Mesbah, A.; Hidalgo, J.; Lauwerier, R.; Bouala, G. I. N.; Parres-Maynadie, S.; Meyer, D.; Dacheux, N.; Podor, R.: Thorium aspartate tetrahydrate precursor to $\mathrm{ThO}_{2}$ : Comparison of hydrothermal and thermal conversions, $J$ Nucl Mater 2017, 487, 331-342.

25. Dacheux, N.; Aupiais, J.: Determination of uranium, thorium, plutonium, americium, and curium ultratraces by photon electron rejecting alpha liquid scintillation, Anal Chem 1997, 69, 2275-2282.

26. Lamarque, N.; Zoppe, B.; Lebaigue, O.; Dolias, Y.; Bertrand, M.; Ducros, F.: Largeeddy simulation of the turbulent free-surface flow in an unbaffled stirred tank reactor, Chem Eng Sci 2010, 65, 4307-4322.

27. Schneider, C. A.; Rasband, W. S.; Eliceiri, K. W.: NIH Image to ImageJ: 25 years of image analysis, Nature Methods 2012, 9, 671-675.

28. Walter, O.; Popa, K.; Dieste Blanco, O.: Hydrothermal decomposition of actinide(IV) oxalates: a new aqueous route towards reactive actinide oxide nanocrystals, Open Chem 2016, 14, 170-174.

29. Rai, D.; Felmy, A. R.; Ryan, J. L.: Uranium(IV) Hydrolysis Constants and Solubility Product of $\mathrm{UO}_{2} \cdot \mathrm{xH}_{2} \mathrm{O}(\mathrm{am})$, Inorg Chem 1990, 29, 260-264.

30. Neck, V.; Kim, J. I.: Solubility and hydrolysis of tetravalent actinides, Radiochim Acta 2001, 89, 1-16. 
31. Faisal, M.; Sato, N.; Quitain, A. T.; Daimon, H.; Fujie, K.: Reaction kinetics and pathway of hydrothermal decomposition of aspartic acid, Int J Chem Kinet 2007, 39, 175-180.

32. Martinez, J.; Clavier, N.; Mesbah, A.; Audubert, F.; Le Goff, X. F.; Vigier, N.; Dacheux, N.: An original precipitation route toward the preparation and the sintering of highly reactive uranium cerium dioxide powders, J Nucl Mater 2015, 462, 173-181.

33. Nazir, M.; Naqvi, I. I.: Synthesis and characterization of uranium (IV) complexes with various amino acids, J Saudi Chem Soc 2010, 14, 101-104.

34. Deguchi, S.; Ghosh, S. K.; Alargova, R. G.; Tsujii, K.: Viscosity measurements of water at high temperatures and pressures using dynamic light scattering, J Phys Chem B 2006, $110,18358-18362$.

35. Bertrand, M.; Plasari, E.; Lebaigue, O.; Baron, P.; Lamarque, N.; Ducros, F.: Hybrid LES-multizonal modelling of the uranium oxalate precipitation, Chem Eng Sci 2012, 77, 95-104.

36. Sung, M. H.; Choi, I. S.; Kim, J. S.; Kim, W. S.: Agglomeration of yttrium oxalate particles produced by reaction precipitation in semi-batch reactor, Chem Eng Sci 2000, $55,2173-2184$.

37. Cilgi, G. K.; Cetisli, H.; Donat, R.: Thermal and kinetic analysis of uranium salts, $J$ Therm Anal Calorim 2014, 115, 2007-2020.

38. Orr, R. M.; Sims, H. E.; Taylor, R. J.: A review of plutonium oxalate decomposition reactions and effects of decomposition temperature on the surface area of the plutonium dioxide product, $J$ Nucl Mater 2015, 465, 756-773.

39. Martinez, J.; Clavier, N.; Ducasse, T.; Mesbah, A.; Audubert, F.; Corso, B.; Vigier, N.; Dacheux, N.: From uranium(IV) oxalate to sintered $\mathrm{UO}_{2}$ : consequences of the powders' thermal history on the microstructure, J Eur Ceram Soc 2015, 35, 4535-4546.

40. Chambon, C.; Vaudez, S.; Heintz, J. M.: De-densification mechanisms of yttria-doped cerium oxide during sintering in a reducing atmosphere, J Amer Ceram Soc 2018.

41. Nkou Bouala, G. I.; Clavier, N.; Lechelle, J.; Mesbah, A.; Dacheux, N.; Podor, R.: In situ HT-ESEM study of crystallites growth within $\mathrm{CeO}_{2}$ microspheres, Ceram Int 2015, 41, 14703-14711.

42. Claparede, L.; Clavier, N.; Dacheux, N.; Mesbah, A.; Martinez, J.; Szenknect, S.; Moisy, P.: Multiparametric Dissolution of Thorium-Cerium Dioxide Solid Solutions, Inorg Chem 2011, 50, 11702-11714.

43. Claparede, L.; Clavier, N.; Dacheux, N.; Moisy, P.; Podor, R.; Ravaux, J.: Influence of Crystallization State and Microstructure on the Chemical Durability of CeriumNeodymium Mixed Oxides, Inorg Chem 2011, 50, 9059-9072. 